\title{
Existence of a Simple Configuration in the Wall Surface of Nocardia Mycelium
}

\author{
By K. TAKEO AND I. UESAKA \\ Department of Bacteriology, Chest Disease Research Institute, \\ Kyoto University, Kyoto, Japan
}

(Received 2 October 1974; revised 5 December 1974)

INTRODUCTION

In Actinomycetales the phylogenetical relationship can be traced from simpler forms to more complex ones. Jensen (1952) presumed that Actinomycetales originated as a unicellular organism, a coryneform bacillus; subsequently, this developed through hyphaproducing organisms to true spore-bearing organisms.

Streptomyces is one of the most differentiated members of the Actinomycetales. It has both vegetative and aerial mycelia, and bears spores only on the aerial mycelium. In ordinary conditions the vegetative mycelium does not divide. Many researchers have studied the ultrastructure of this organism by means of freeze-etching, carbon replica, and negative staining (Vernon, I955; Hopwood \& Glauert, I96I; Wildermuth, Wehrli \& Horne, 1971; Williams et al. 1972). They found beautiful arrays of 'rodlets' on the extracellular coat of the spore and aerial mycelium in some species.

The genus Nocardia also has aerial and vegetative mycelia, but the difference between them is not as distinct as is found in Streptomyces and some other Actinomycetales. Both forms of mycelia have the ability to fragment into bacillary or coccoid elements which serve to propagate. Thus, Nocardia seems to be located in an intermediate position, between true spore-bearing organisms and Mycobacterium or other unicellular organisms. Its ultrastructure has been studied by Kawata \& Inoue (I965) and Beaman \& Shankel (I969), using thin sectioning or freeze-etching, but they did not describe its surface structure. No carbon replica or negative staining studies have been reported.

This paper describes a linear configuration found in the wall surface of Nocardia asteroides and Nocardia brasiliensis by means of freeze-etching, and discusses its relationship to the rodlets of Streptomyces.

\section{METHODS}

The organisms used were stock cultures in this laboratory. They were grown either on glycerol nutrient agar ( $10 \mathrm{~g}$ glycerol, Io g polypeptone, Io $\mathrm{g}$ meat extract, $2 \mathrm{~g} \mathrm{NaCl}$ and $20 \mathrm{~g}$ agar/l water) or in glycerol nutrient broth, with shaking, at 25 or $30^{\circ} \mathrm{C}$ for 2 to 5 days. The growths were fixed for a few days at $4{ }^{\circ} \mathrm{C}$ with $2.5 \%$ glutaraldehyde containing $0.07 \mathrm{M}$-phosphate buffer $\mathrm{pH} 7.2$, then cryoprotected against ice-crystal formation by immersing in $30 \%$ glycerol overnight at $4{ }^{\circ} \mathrm{C}$. Freeze-etching was done as described previously (Takeo et al. 1973). 

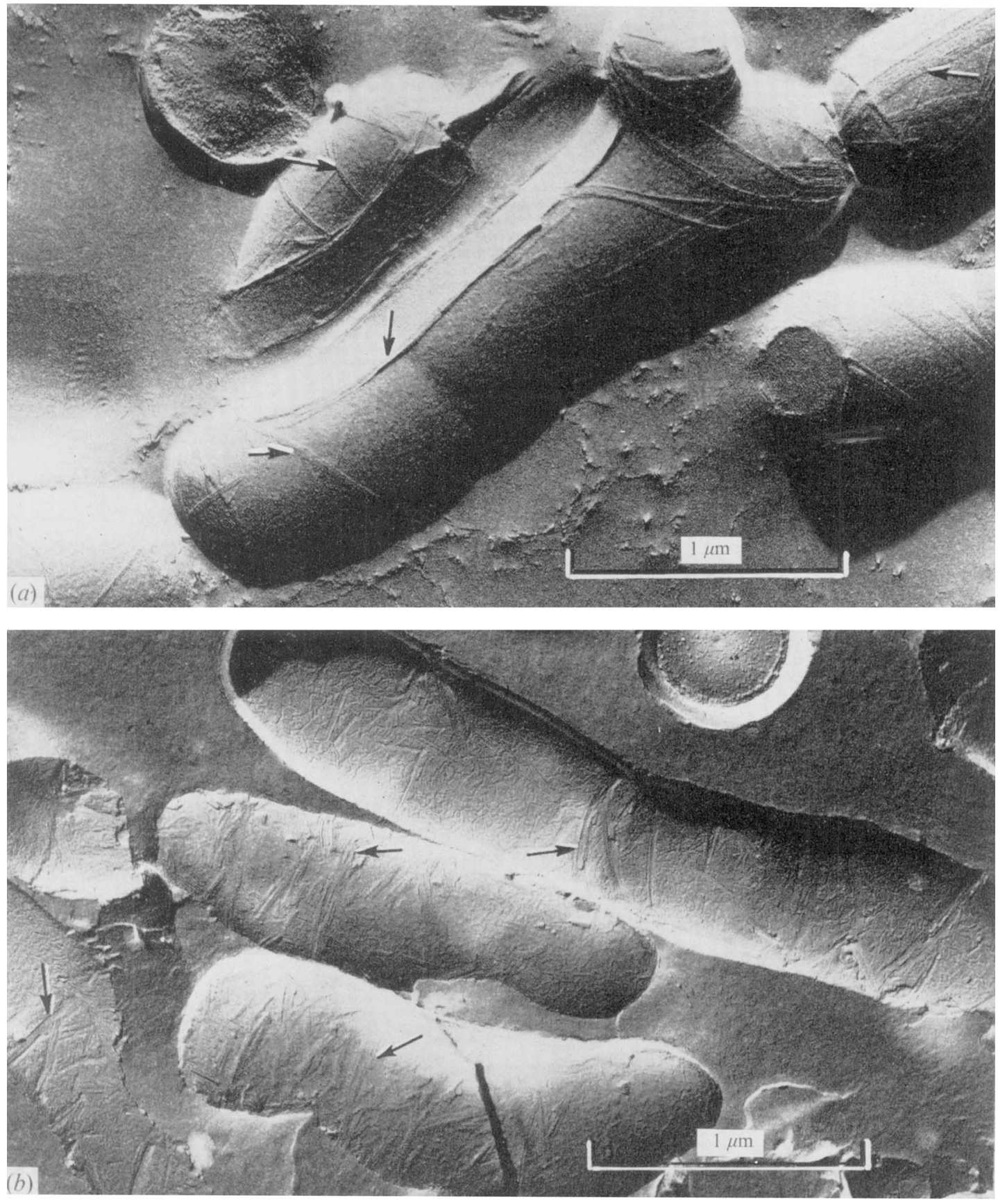

Fig. I. (a) Freeze-etched mycelia of $N$. brasilienis grown on a glycerol nutrient agar plate for 3 days at $25^{\circ} \mathrm{C}$. Note linear structures on the wall surfaces (arrows). (b) Freeze-etched mycelia of $N$. asteroides grown in glycerol nutrient broth, with shaking, for 2 days at $30^{\circ} \mathrm{C}$. Linear configurations are seen as in (a) (arrows). 


\section{RESULTS AND DISCUSSIONS}

Fig. I (a) shows $N$. brasiliensis grown on an agar plate. Mycelia of Nocardia almost always freeze-fractured along the cell surface. This characteristic is the same as found in Mycobacterium (M. Nishiura \& K. Takeo, unpublished) and seems to offer further evidence for the relationship of the two genera, in addition to the well-known acid-fastness, major cell wall constituents, and mycolic acids in a broader sense (Lechevalier, Lechevalier \& Gerber, I97I). However, Nocardia wall surface revealed an additional feature: linear structures were superimposed on the surface layer of the wall (Fig. I (a). They were about $20 \mathrm{~nm}$ wide about the same size as the rodlets found earlier in the spore or the aerial mycelium of some species of Streptomyces (Wildermuth et al. 197I). However, the surface configuration of Nocardia is much simpler than that reported in Streptomyces. The rodlets of Streptomyces cover the whole surface of the spore and aerial mycelium with local regularity, and they are about the same length $(200 \mathrm{~nm})$. The linear structures of Nocardia were sometimes long enough to encircle the cell wall and were only sparsely distributed on the surface layer (Fig. I a). This linear structure seems to be characteristic of Nocardia, as no other reports of it have been made. We shall refer to it as 'Nocardia lines' or 'N-lines'. Nocardia asteroides grown on agar plate also showed clear $\mathrm{N}$-lines on the surface of the wall. The size and abundance of the lines were about the same as those for $N$. brasiliensis.

Fig. I (b) shows $N$. asteroides grown in submerged culture, with shaking. As seen in Fig. I $(b)$, almost all cells possessed N-lines; this was also true in $N$. brasiliensis. Since it may reasonably be assumed that most mycelia in submerged culture are vegetative, the vegetative as well as the aerial mycelia of Nocardia have N-lines. In Streptomyces, on the other hand, the spore and wall surfaces of aerial mycelia are entirely covered with the rodlets, while the vegetative mycelium shows no rodlets and does not freeze-fracture along the wall surface (Williams et al. 1972). Our results provide further evidence that in Nocardia the difference between the aerial and vegetative mycelia is only slight, if any.

Thermoactinomyces is also reported to have a surface configuration made by rodlets which resembles that of Streptomyces (McVittie, Wildermuth \& Hopwood, 1972), and the same applies to the spores of many fungi (Hess, Sassen \& Remsen, 1968; Hess \& Stocks, I969; our unpublished data). However, nobody has reported the existence of the surface configuration in non-spore-generating organisms. It may thus be said that the surface configuration made by the rodlets is specifically found in spore-bearing micro-organisms, and that the $\mathrm{N}$-line is a forerunner of the complicated surface configuration. Of course, Nocardia itself cannot be regarded as a forerunner of Streptomyces or Thermoactinomyces, as the data of cell wall constituents show (Lechevalier et al. 197I). However, a forerunner of Streptomyces may reasonably be supposed to have an aerial mycelium less clearly differentiated from its vegetative mycelium than in Streptomyces, and to have a simple surface configuration such as that found in Nocardia. In this sense, we suggest that the N-line links the presence of the complicated surface configuration in Streptomyces on the one hand, and the absence of surface configuration in Mycobacterium and other unicellular microorganisms on the other.

We thank Mr H. Yamada, Mrs E. Yamagishi, Mrs Y. Takaoki and Mr T. Nonaka for technical assistance. 


\section{REFERENCES}

BeAman, B. L. \& Shankel, D. M. (1969). Ultrastructure of Nocardia cell growth and development on defined and complex agar media. Journal of Bacteriology $99,876-884$.

Hess, W. M., Sassen, M. M. A. \& Remsen, C. C. (1968). Surface characteristics of Penicillium conidia. Mycologia 60, 290-303.

Hess, W. M. \& Stocks, D. L. (1969). Surface characteristics of Aspergillus conidia. Mycologia 6r, 560-57I.

Hopwood, D. A. \& Glauert, A. M. (I96r). Electron microscope observations on the surface structures of Streptomyces violaceoruber. Journal of General Microbiology 26, 325-330.

JENSEN, H. L. (1952). The coryneform bacteria. Annual Review of Microbiology 6, 77-90.

KaWATA, T. \& INOUe, T. (1965). Ultrastructure of Nocardia asteroides as revealed by electron microscopy. Japanese Journal of Microbiology 9 , IOI-1 14.

Lechevalier, H. A., Lechevalier, M. P. \& Gerber, N. N. (I97I). Chemical composition as a criterion in the classification of actinomycetes. In Advances of Applied Microbiology, vol. 14, pp. 47-72. Edited by D. Perlman. New York and London: Academic Press.

McVittie, A., Wildermuth, H. \& Hopwood, D. A. (I972). Fine structure and surface topography of endospores of Thermoactinomyces vulgaris. Journal of General Microbiology 71, 367-381.

TaKeo, K., Uesaka, I., Uehira, K. \& Nishiura, M. (1973). Fine structure of Cryptococcus neoformans grown in vitro as observed by freeze-etching. Journal of Bacteriology $1 \mathbf{1 3}_{3}, 1442-1448$.

Vernon, T. R. (1955). Spore formation in the genus Streptomyces. Nature, London 176, 935-936.

Wildermuth, H., Wehrli, E. \& Horne, R. W. (I97I). The surface structure of spores and aerial mycelium in Streptomyces coelicolor. Journal of Ultrastructure Research 35, 168-180.

Williams, S. T., Bradshaw, R. M., Costerton, J. W. \& Forge, A. (I972). Fine structure of the spore sheath of some Streptomyces species. Journal of General Microbiology 72, 249-258. 